\title{
HIILAH: ANTARA SOLUSI DAN MANIPULASI DALAM HUKUM ISLAM
}

\author{
Oleh: \\ Ahmad ${ }^{1}$ \\ Email: ahjelly@gmail.com
}

\begin{abstract}
Islamic law is a set of laws born of Islam as a benchmark of the legality of a servant's deeds. There is no Muslim act as complex as anything apart from aspects of Islamic law. Thus, Islamic law will always be present to be a solution to the complexity of life's problems faced by humans. In reality, a Muslim not only finds the complexity of problematics in the aspects of the reality of life, but also occurs in the process of istinbath Islamic law itself. So in the process istinbath, Islamic law that should be a solution precisely be the manipulation of Islamic law itself. The complexity of the istinbath process of Islamic law itself can be found in a concept called hiilah.
\end{abstract}

Keywords: Hiilah, Islamic law, the problematic of Islamic law.

\section{Pendahuluan}

Dalam setiap sendi kehidupan, manusia selalu berhubugan dengan syariát (الشريعة)2. Tidak ada aspek perbuatan manusia yang tidak luput dari jangkauan syariát. Sementara syari'at merupakan pengejawantahan dari keberagamaan (التدين). Dalam tataran aplikasi, syariát dijabarkan secara lebih spesifik dalam penjelasan Hukum Islam ( الحكم الشرعي dalam bentuk jamak

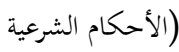

Hukum Islam dalam proses kemunculannya lahir dari sebuah $k h i t h o b^{3}$. Dalam terminologinya, hukum didefinisikan sebagai khithob

${ }^{1}$ Dosen STAI Syaichona Moh. Cholil Bangkalan

2 Syari'at secara etimologi diartikan sebagai jalan yang bisa ditempuh agar bisa sampai pada sumber air (الطريق الذي يتوصل به إلى الماء). Sementara secara terminologi Syari'at diartikan sebagai semua hal yang telah dimulaikan oleh Allah kepada manusia dalam bentuk agama dan hukum-hukum-Nya ( ما شر عه اله لعباده من الدين وأحكامه (Muhammad Mahmud Hijaziy. At-Tafsir al-Wadhih. Maktabah Syamilah. Juz 1 Hlm 521).

${ }^{3}$ Khitob didefinisikan sebagai firman Allah secara hakiki pada zaman Azali. Syamsuddin. Hasyiyah al-Allamah al-Bannani ála Matn Jamíl Jawami'. Beirut Lebanon. Dar al-Fikr. 2003. Juz 1 Hlm 175. 
Allah yang berhubungan dengan perbuatan mukallaf, baik secara iqtidlo' 4 (اقتضاء) atau secara wadlíy ${ }^{5}$ (وضا). Sementara dalam tataran praktis, hukum Islam ( الحكم الشرعي ) lebih dikenal dengan fiqh ${ }^{6}$. Proses untuk menemukan, menggali, dan mengeluarkan hukum Islam diproses dalam Ushul Fiqh7 . Kompilasi hukum-hukum Islam tersarikan dalam bentuk Qawa'id Fiqh8. Sementara kompilasi proses untuk menemukan, menggali, dan mengeluarkan hukum Islam tersarikan dalam Qawaid Ushul Fiqh ${ }^{9}$.

\section{Ketentuan-ketentuan Dasar dan Problematika Hukum Islam}

Bahwa dalam hukum Islam terdapat ketentuan-ketetuan dasar yang harus diketahui dalam proses penerapannya. Ketentuan-ketentuan dasar ini lantas menjadi ukuran akibat atau status hukum yang dikenainya.

a. Halal dan haram (حلال أو حرام)

Pada prinsipnya, Allah sebagai Syari' telah menetapkan dan menjelaskan mana yang halal dan mana yang haram. Bahwa perbuatan halal sudah jelas dan perbuatan haram juga sudah jelas, dan diantara perbuatan halal dan haram terdapat perkara syubhat ${ }^{10}$. Perbuatan atau barang halal akan berkonsekuensi pada status hukum antara wajib, sunnah, dan mubah. Sementara perbuatan atau barang haram akan

${ }^{4}$ Iqtidlo' sering disebut juga dengan taklifiy yaitu pembagian hukum menjadi wajib, mandub, mubah, makruh dan haram. Zakariya al-Anshori. Ghayatul Wushul Fi Syarhi Lubbil Ushul. Surabaya: al-Hidayah. Juz 1 hlm 5.

5 Wadl'iy adalah sekumpulan hukum yang disematkan/melekat kepada hukum taklifiy yaitu berupa sah (صحيح), batal (بطلان), fasad (), mani' (مانع), syarat (شرط), sebab (سبب). Ibid. Zakariya al-Anshori. Ghayatul Wushul Fi Syarhi Lubbil Ushul. Hlm 1 juz 5.

${ }^{6}$ Fiqh adalah mengetahui hukum-hukum syariát yang bersifat perbuatan seharisehari, yang diperoleh melalui dalil-dalil terperinci (tafsilily). Abd. Wahhab Khollaf. Ushul Fiqh. Beirut Lebanon: Dar al-Fikr. Hlm 10.

${ }^{7}$ Ushul Fiqh adalah mengetahui hukum-hukum syariát yang bersifat perbuatan sehari-sehari, yang diperoleh melalui dalil-dalil yang masih global (ijmal). Ibid. Abd. Wahhab Khollaf. Ushul Fiqh. Beirut Lebanon: Dar al-Fikr. Hlm 10

${ }^{8}$ Qawaid Fiqh adalah rumusan-rumusan umum yang diambil dari realitas fiqh yang terbentuk.

${ }^{9}$ Qawaid Ushul Fiqh adalah rumusan-rumusan umum yang diambil dari teori-teori dalam Ushul Fiqh.

${ }^{10}$ Hadits Nabi الحلال بين والحرام بين وما بينهما أمور مشتبهات. hadits ini termasuk hadits yang banyak diriwayatkan oleh banyak perawi Hadits. Ibn Majah. Sunan Ibn Majah. Maktabah Syamilah. Juz 2 hlm 1318. 
berkonsekuensi pada status hukum haram, sementara perbuatan syubhat setidak-tidanya akan berkonsekuensi pada makruh dan yang lebih tinggi berakibat haram juga.

b. Kemudahan atau main-main (يسر أو تلاعب)

Bahwa salah satu dalam prinsip dasar agama adalah adanya prinsip kemudahan. Agama Islam hadir untuk membebaskan manusia dari belenggu kesulitan. Demikian jelas prinsip agama ini, sampai-sampai Nabi dalam seluruh praktek sunnahnya selalu mengedepankan kemudahan ${ }^{11}$. Namun demikian, kemudahan yang sudah diberikan oleh agama tidak boleh menyebabkan turun pada derajat meremehkan dan bermain-main dalam agama.

c. Toleransi dan azimah (رخصة أو عزئة)

Salah satu bentuk wujud dari prinsip kemudahan dalam agama Islam adalah adanya bentuk rukhshoh ${ }^{12}$.

d. Tujuan syari'at (مقاصد الشريعة)

Tidak dipungkiri bahwa tujuan keberadaan hukum Islam bermuara pada dua kemungkinan yaitu manfaat/maslahat (منعة أو مصلحة ) dan mafsadah/mudarat ( مفسدة أو مضرة). Bahwa segala apapun yang dapat mengantarkan pada manfaat dan maslahat pasti akan diperbolehkan, sementara segala apapun yang mengantarkan dan menyebabkan pada mafsadah/mudarat pasti tidak akan diperbolehkan. Terdapat klasifikasi manfaat/maslahat dan mafsadah/mudarat yang lalu kemudian menjadi perdebatan yaitu: akhirat dan duniawi, manakah yang harus didahulukan. Sekilas, jika istilah yang dimunculkan akhirat dan duniawi maka tampak jelas mana yang harus didahulukan. Namun dalam tataran praktis, mana yang disebut dengan maslahat atau mafsadat akhirat atau duniawi maka apa yang tampak mudah akan menjadi sulit. Sebagai contoh, nyawa dan mengucapkan kata $k u f r$. Saat

${ }^{11}$ Hadits Nabi ما خير رَسُول اللهِ صَلَّى اللهُ عَلَيْهِه وَسَلَّمَ بين أمرين قط ، إلا أخذ بأيسر هما. al-Khodlriy. Musnad Abi Áwanah. Maktabah Syamilah. Juz 2 hlm 140.

12 Rukhshoh didefinisikan sebagai hukum yang berubah menjadi lebih mudah dikarenakan ada udzur (alasan) bersamaan dengan adanya sebab (سبب) terhadap hukum asal. Ibid. Zakariya al-Anshori. Ghayatul Wushul Fi Syarhi Lubbil Ushul. Hlm 1 juz 11. 
kondisi terpaksa (baca: terancam mati) seseorang diperbolehkan mencupakan kata-kata kufri3.

e. Hak Allah dan hak manusia (حق الله أو حق الأدمي)

Secara umum, klasifikasi hak dalam hukum Islam terbagi menjadi dua yaitu hak Allah dan hak manusia. Semua hukum yang bermuara pada hak Allah maka manusia tidak mempunyai pilihan untuk merubahnya, sementara hukum yang bermuara pada hak manusia, manusia mempunyai pilihan untuk merubahnya.

f. Tujuan dan sarana (مقصد أو وسيلة)

Bahwa hukum yang bermuara dan berhubungan dengan tujuan maka selalu bersifat pasti, tegas dan tidak bisa berubah. Sementara hukum yang bermuara dan berhubungan dengan sarana maka bersifat elastis, bisa berubah dan toleran.

Selanjutnya, ketentuan-ketentuan dasar tersebut dalam tataran praktisnya, justru menjadi objek problematika hukum Islam itu sendiri. Hal ini disebabkan karena ada perbedaan-perbedaan dalam memahami, menggali, penafsiran terhadap ketentuan-ketentuan dasar tersebut. Perbedaan-perbedaan dalam memahami, menggali, dan penafsiran terhadap ketentuan-ketentuan dasar antara lain:

a. Perbedaan dalam penggunaan nash atau dalil syari'ah

Perbedaan dalam penggunaan nash atau dalil syari'ah disebabkan karena perbedaan dalil yang dipakai dalam satu masalah. Sebagai ilustrasi, satu pendapat menggunakan ayat al-Qur'an yang satu, pendapat yang lain menggunakan pegangan ayat yang lain, satu pendapat menggunakan istihsan, dan pendapat yang lain menggunakan qiyas, dan begitu seterusnya.

b. Perbedaan dalam memaknai dan menafsirkan nash atau dalil syari'ah

Perbedaan dalam penggunaan nash atau dalil syari'ah disebabkan karena dalam memaknai antara qothi'iy dan dhonniy, antara rasional (معقول المعنى ) dan murni ibadah (غير معقول المعنى أو تعبدي).

c. Perbedaan dalam melihat realitas

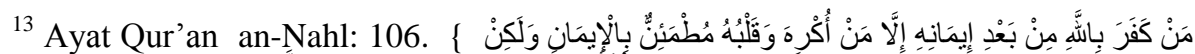

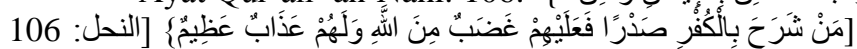


Tidak dapat dipungkiri bahwa satu realitas dapat mempunyai dimensi aspek hukum yang berbeda-beda. Perbedaan realitas ini pada akhirnya menyebabkan pada perbedaan status hukum. Sebagai ilustrasi, perbedaan realitas melahirkan status hukum yang berbeda, yaitu tatkala Baginda Nabi Muhammad memberikan status hukum orang yang mencium isterinya dalam kondisi berpuasa; satu orang oleh Nabi diberikan status boleh-boleh saja (puasanya tetap sah), sementara orang yang berbeda diberikan status tidak boleh (haram dan menyebabkan puasanya batal) ${ }^{14}$.

d. Perbedaan dalam menggunakan,memaknai, menafsirkan maqoshid as-Syari'ah

Perbedaan dalam menggunakan, memaknai, menafsirkan maqoshid as-Syari'ah juga berdampak pada perbedaan hukum yang ditimbulkan. Sebagian pendapat menempatkan maqoshid as-syari'ah berada di bawah nash atau dalil syari'ah, sementara pendapat yang lain mendahulukan maqoshid as-syari'ah sambil lalu melakukan pemaknaan bahwa nash atau dalil Syari'ah yang dimaksud masih dhonniy, umum (عام), belum jelas dan lain sebagainya.

\section{Alternatif Hiilah}

Manusia diciptakan sebagai makhluk berakal, pemikir, perenung15. Kemampuan ini mendorong manusia mampu melakukan penalaran hingga sampai pada posisi mengidentifikasi, menemukan, dan memecahkan masalah. Akhirnyapun manusia disebut manusia terbaik karena mampu melakukan kreasi, inovasi, dan menciptakan solusi. Kemampuan kreasi, inovasi, dan menciptakan solusi dalam sejarah otak manusia telah digugah sendiri oleh Tuhan. Saat Habil berada dalam kebingungan telah membunuh saudara kandungnya (Qobil), Tuhan mengilhamkan kepada Habil kemampuan kreasi, inovasi, dan

${ }^{14}$ KH. Afifuddin Muhadjir. Membangun Nalar Islam Moderat. Situbondo: Tanwirul Afkar. Hlm 45.

${ }^{15}$ Ayat Qur'an tentang kemampuan manusia berakal, berpikir dan merenung. 
menciptakan solusi berupa kemampuan meniru tindakan burung gagak yang menggali-gali tanah untuk menguburkan burung yang mati ${ }^{16}$.

Kemampuan kreasi, inovasi dan menciptakan solusi tak terbatas dalam satu masalah, namun juga terjadi dalam ruang lingkup hukum Islam. Dalam sejarahnya, manusia terus berusaha melakukan kreasi, inovasi dan menciptakan solusi terhadap problematika hukum Islam. Kemunculankemunculan berbagai macam teori tentang metode istinbath hukum Islam, nash syari'ah, dalil syari'ah, dan lain sebagaimanya merupakan hasil kreasi, inovasi, dan solusi yang diciptakan ulama' untuk menyelesaikan problematika hukum Islam. Salah satu bentuk konsep dalam metode istinbath hukum Islam yang erat kaitannya dengan kemampuan manusia melakukan kreasi, inovasi, dan solusi adalah hiilah.

Hiilah (الحيلة جالحيل ) secara bahasa berarti kecerdikan dalam mengurus

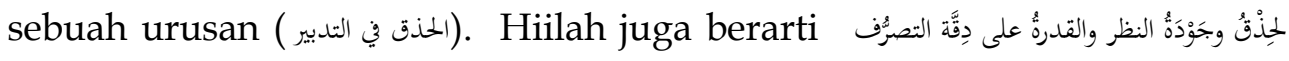
yaitu kecerdikan, kepandaian menganalisa, dan kemampuan merespon

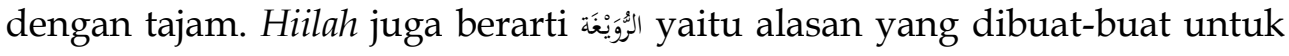
melepaskan diri. Ibrahim Unais menambahkan makna kata ini dengan بريلة بارعة تحيل الشيء عن ظاهره ابتغاء الوصول إلى المقصود yaitu jalan cerdas yang mengalihkan sesuatu dari tampaknya untuk sampai ke tujuan. Di antara ulama, ada juga yang menggunakan istilah ihtiyal (mencari hiilah).

Sementara secara terminologi hiilah berarti membalik sudut pandang berpikir untuk mencapai pada tujuan yang dimaksudkan (تقليب الفكر حتى يهتدي (إلى المقصود (Definisi ini banyak dikemukakan oleh banyak Ulama'. Definisi yang hampir sama dikemukakan oleh Ibn Hajar dalam kitabnya Fathul Bari, hiilah adalah cara yang dipakai untuk sampai pada tujuan yang

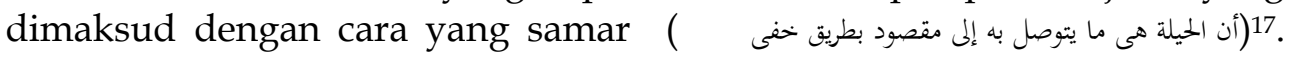
Hampir semua ulama' sepakat akan keniscayaan keberadaan konsep hiilah. As-Syatibiy memberi pengertian hiilah dengan pengertian mendahulukan perbuatan yang secara dhohir dibolehkan dengan tujuan untuk membatalkan sebuah hukum syari'at dan merubahnya pada hukum yang

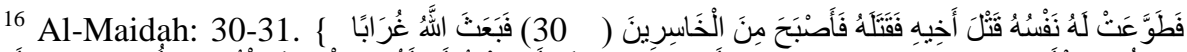

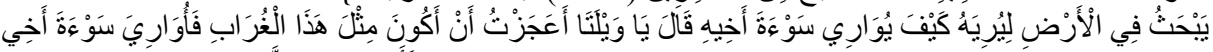

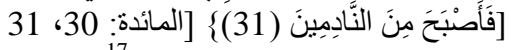

${ }^{17}$ Ibn Hajar. Fathul Bari. Maktabah Syamilah. Juz 19 hlm 417.
} 


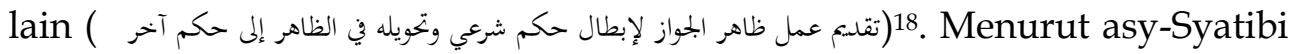
konsep hiilah mempunya tujuan akhir untuk mencari celah dan menyiasati hukum syari'at.

\section{Dalil Hiilah}

Dalam nash Qurán dan Hadits, terdapat dua pemaknaan hiilah. Pertama: hiilah yang disyariátkan (حيلة مشروعة). Kedua: hiilah yang diharamkan (حيلة حرمة). Dalil-dalil terhadap hiilah yang disyariátkan sebagai acuan bahwa hiilah dianggap sebagai solusi terhadap problematika hukum Islam adalah sebagai berikut.

1. Ayat al-Qur'an

a. Kisah Nabi Ayyub

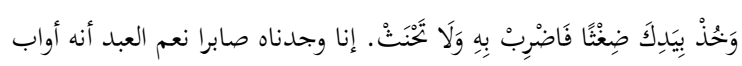

Ayat ini mengisahkan tentang Nabi Ayyub yang pernah bersumpah memukul isterinya seratus kali karena pernah terlambat dalam suatu urusan. Lalu Allah memerintahkan untuk mengambil sejumput rumput sebagai ganti seratus pukulan ${ }^{19}$. Dengan cara ini Nabi Ayyub bisa mendapatkan solusi janji memukul isterinya seratus kali pukulan diganti dengan 100 rumput dengan hanya satu kali pukulan.

b. Kalimat kufr dalam keadaan terpaksa

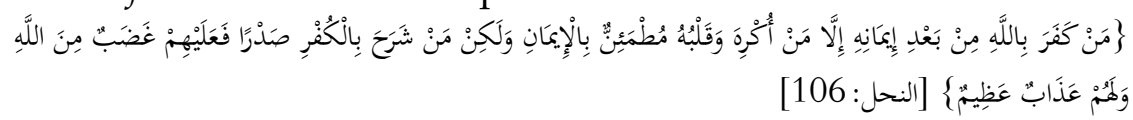

Ayat ini menceritakan tentang kebolehan mengucapkan kalimat $\mathrm{kufr}$ dalam keadaan terpaksa.

c. Kondisi tidak ada pilihan/hiilah

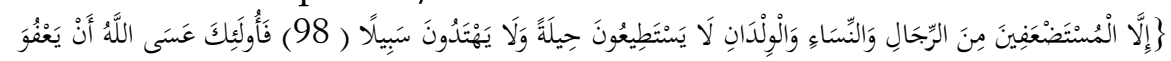

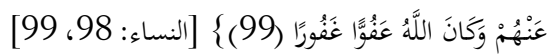

${ }^{18}$ Abu Ishaq al-Syathibi. al-Muwāafaqāt fì Ushul al-Syarī'ah. Maktabah Syamilah. Juz 4 hlm 201.

${ }^{19}$ Syaikh Jalaluddin. Tafsir Jalalain. Maktabah Syamilah. Juz 09 Hlm 25. 
Ayat ini berisi tentang status orang-orang yang tidak mempunyai pilihan (solusi) dalam proses kehidupannya, maka Allah akan mengampuni dosa.

\section{Hadits}

Nabi Muhammad pernah mempraktekkan konsep hiilah sebagaiman tertera dalam sebuah hadits berikut.

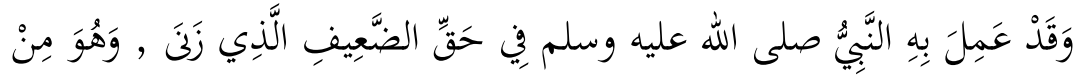

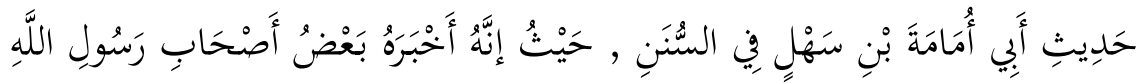

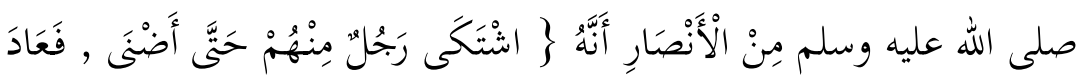

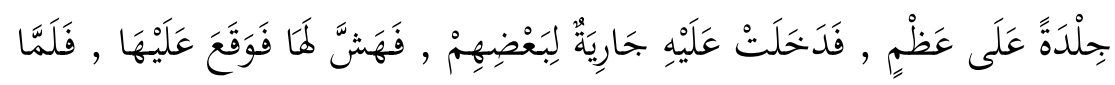

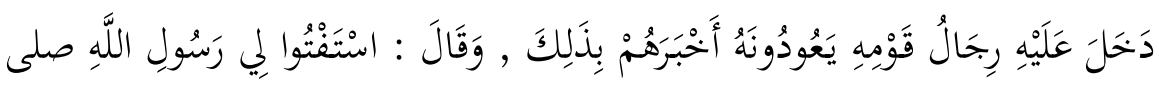

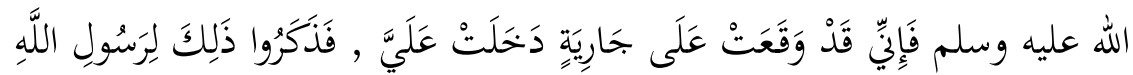

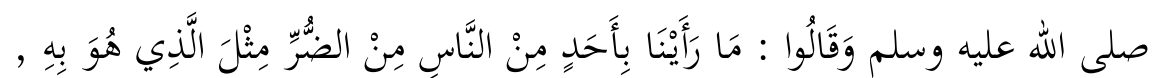

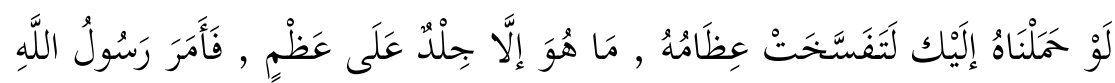

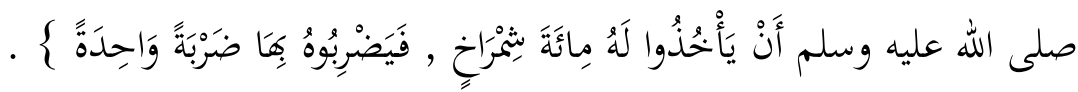

Hadits ini mengisahkan tentang sahabat Nabi yang berada dalam kondisi sakit parah, hingga kondisinya digambarkan hanya tinggal kulit dan tulang. (Namun demikian) Sang sahabat tertarik pada seorang perempuan (pelayaan) yang datang menjenguknya hingga akhirnya berzina. Saat diadukan pada Nabi Muhammad, para sahabat merasa iba karena kondisinya yang sedang sakit parah. Sebagai bentuk penegakan hukum, Nabi tetap melakukan hukuman cambukan atas sang sahabat dengan cara mengambil seratus tangkai ranting pohon anggur dan memukulkannya satu kali (sebagai ganti 100 kali cambukan).

Demikian juga dalam praktek yang lain, Nabi pernah menyampaikan sebuah hadits. 


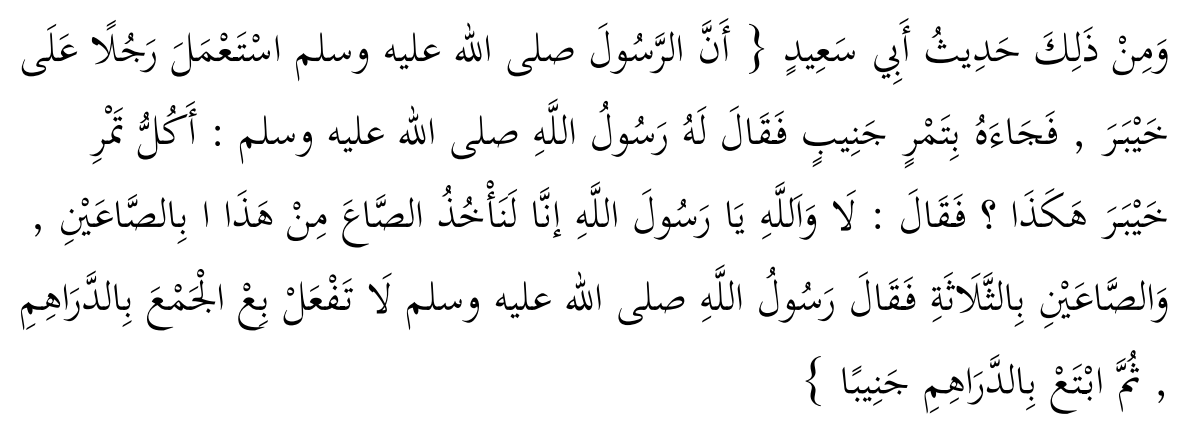

Hadits ini mengisahkan saat Nabi mempekerjakan seorang pekerja di tanah Khoibar. (Sebagai hasilnya) sang pekerja lalu datang membawakan hasil tanam Khoibar berupa satu keranjang kurma yang baik. Lalu Nabi bertanya "apakah semua kurma Khoibar sebagus ini semua?". "Tidak ya Rasulullah (kurma Khoibar tidak semuanya hasilnya bagus, sebagian bagus sebagian yang lain lagi tidak bagus). Kami (biasa) menukar satu keranjang kurma yang bagus dengan dua keranjang yang kurang bagus. Nabi lalu menanggapi. "jangan lalukan itu lagi, sebaiknya dua keranjang kurma yang bagus dijual terlebih dahulu (dengan dirham) lalu uang (dirham) nya dibelikan untuk sekeranjang kurma yang bagus.

Muatan sejenis terdapat dalam hadits:

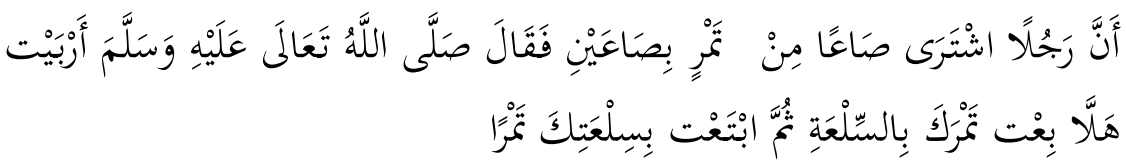

Dalam Hadits ini Nabi Muhammad melarang seseorang membeli sekeranjang kurma (yang baik) dengan dua keranjang (yang kurang baik) karena praktek ini menyebabkan riba. Hiilah (solusinya) jual dulu kurmanya lalu hasilnya dibelikan dengan kurma yang lain ${ }^{20}$.

${ }^{20}$ Ibn Nujaim. Al-Asyah wa al-Nazhair li ibn Nujaim. Maktabah Syamilah. Hlm 406. 


\section{Alasan rasional}

Pada prinsipnya setiap muslim diwajibkan untuk terbebas dari perbuatan haram, dan mengerjakan perbuatan yang disyariátkan ${ }^{21}$. Inilah hakikat takwa yang sesungguhnya. Dengan demikian, segala usaha agar bisa melakukan perbuatan yang disyariátkan dan terbebas dari perbuatan haram disyariátkan pula. Sesuai dengan kaidah sebabakibat dalam perbuatan wajib22. Demikian juga, hiilah yang diharamkan disebabkan karena hiilah tersebut bertentangan dengan nash syariát dan mashlahat syariát. Sehingga jika ada hiilah yang tidak bertentangan dengan nash syariát dan mashlahat syariát maka tentu diperbolehkan dan disyariákan pula.

Sebagaimana seorang muslim dalam kondisi terpaksa diperbolehkan untuk mengucapkan kata-kata kufr, sebagaimana halnya Islam menggaransi siapapun yang telah berikrar dalam Islam ${ }^{23}$.

Sementara dalil-dalil terhadap hiilah yang diharamkan sebagai dasar bahwa hiilah adalah bentuk manipulasi dan usaha mengelabui Hukum Islam adalah sebagai berikut.

1. Al-Qurán

Kisah Bangsa Israel

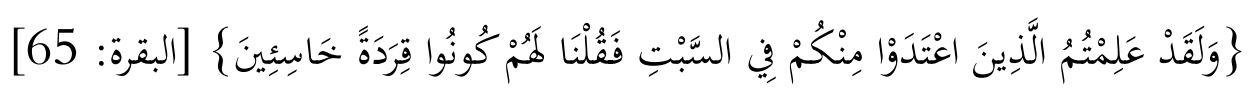

Ayat ini menceritakan tentang celaan terhadap orang-orang Yahudi yang melakukan hiilah (manipulasi dan cari-cari alasan) terhadap larangan berburu (melaut menangkap ikan) di hari Sabtu. Atas larangan ini, lalu orang-orang Yahudi mencari-cari cara menyiasati larangan ini dengan cara mereka membuat parit dari laut untuk kemudian dibuat perangkap. (memang) Pada hari Sabtu mereka

${ }^{21}$ Ibid. Ibn Qoyyim. Sad adz-Dzara'i wa tahriim al-Hiyal li Ibn Qoyyim. Juz 1 hlm

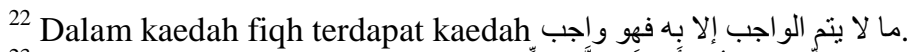

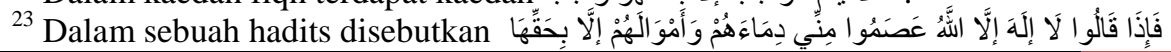


tidak pergi melaut, mereka hanya membuka gerbang parit di pinggir laut. Mereka baru memanennya pada hari Ahad. Saat orang-orang Yahudi ditegur atas larangan berburu (menangkap ikan) di hari Sabtu, mereka beralasan "bukankah kita tidak berburu (menangkap ikan) di hari Sabtu, melainkan di hari Ahad." Atas tindakan hiilah (manipulasi dan cari-cari alasan) inilah, Allah mengadzab orang-orang Yahudi dengan adzab berubah rupa menjadi kera ${ }^{24}$.

2. Hadits

Larangan melakukan hiilah juga banyak disampaikan oleh Nabi Muhammad.

a. Larangan meniru Israel

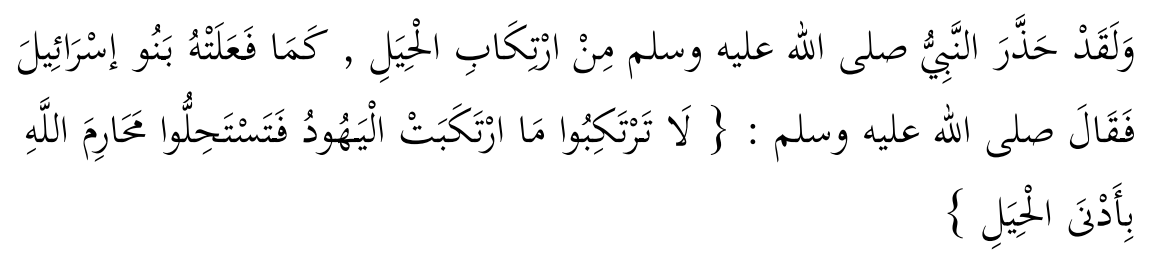

Dalam hadits ini, Nabi Muhammad memperingatkan para sahabatnya (dan juga umatnya) untuk tidak melakukan perbuatan sebagaimana perbuatan yang dilakukan oleh Bangsa Israel yaitu suka melakukan hiilah.

b. Mensiasati bentuk

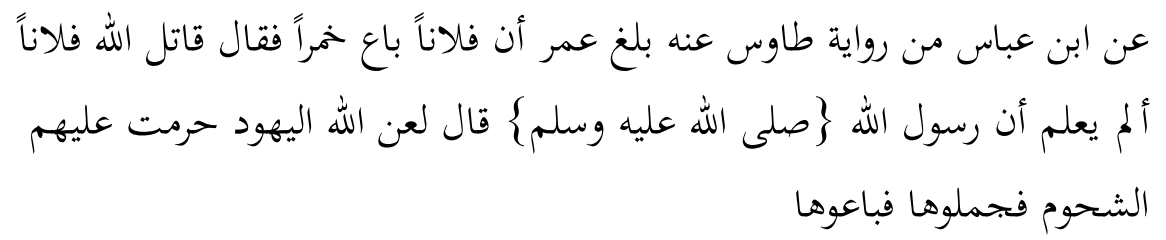

Dalam hadits ini, Nabi Muhammad menggambarkan bahwa Bangsa Israel dilaknat oleh Allah karena mereka melakukan hiilah atas larangan menjual lemak (hewan bangkai) dengan cara

${ }^{24}$ Abu Jakfar Muhammad Ibn Jariir at-Thobari. Jami'ul Bayan fi Tafsiril Qur'an lit Thobari. Maktabah Syamilah. Juz 2 hlm 64. 
mencairkan dan menjadikannya minyak terlebih dahulu lalu mereka menjualnya ${ }^{25}$.

c. Mengganti Nama

أنه سمع النبي صلى الله عليه وسلم يقول ليشربن ناس من أمتي الخمر يسمونا بغير

Dalam hadits ini, Nabi Muhammad mengingatkan bahwa akan ada manusia (dari umatku) yang minum khomr dan mereka menamakannya dengan nama yang berbeda ${ }^{26}$. Demikian juga larangan hiilah dengan cara mengganti nama terdapat dalam hadits.
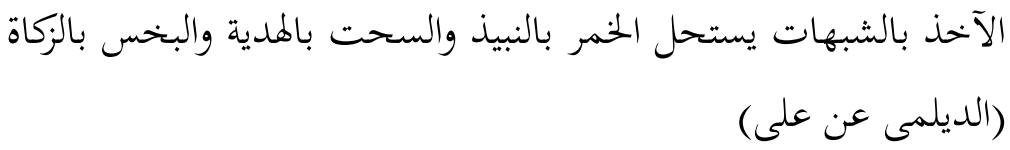

Bahwa orang-orang yang terjebak pada perkara syubhat akan menghalalkan khamr dengan (mengganti nama) perasan anggur, suap dengan (ganti nama) hadiah, bakhs (yaitu mengambil upeti tambahan dari rakyat) dengan zakat ${ }^{27}$.

d. Pernikahan (main-mata) Muhallil

عن على بن أبى طالب رضى الله عنه قال لعن رسول الله صلى الله عليه وسلم الحال والمحلل

Pada dasarnya, seorang perempuan yang telah ditalak 3 oleh suaminya tidak boleh kembali lagi kecuali telah menikah lagi dengan orang lain (muhallil). Namun demikian, Nabi justru melaknat pernikahan (main mata) antara suami kedua (muhallil)

25 Buchori Muslim. Al-Jamú Baina al-Shohihain li Buchori Muslim. Maktabah Syamilah. Juz 1 hlm 35.

${ }^{26}$ Ahmad. Musnad Ahmad al-Risalah. Maktabah Syamilah. Juz 10 hlm 478.

${ }^{27}$ As-Suyuthi. Jami'al-Hadits li as-Suyuthi. Maktabah Syamilah. Juz 37 hlm 534. 
dengan suami pertama (muhallal lah)28. Dengan demikian pernikahan (main mata) antara muhallil dan muhallal lah adalah haram. Keharaman ini disebabkan karena pernikahan ini hanya dijadikan hiilah (siasat) atas keharaman perempuan yang telah ditalak 3.

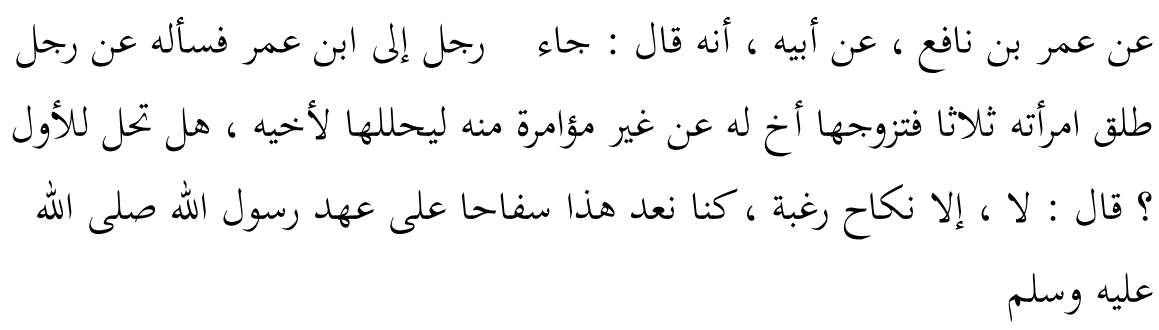

Dalam penjelasan yang lebih jelas, Ibn Umar bahkan mempertegas bahwa pernikahan hanya bisa terjadi jika ada didasari atas rasa kasih sayang dan masa Rasulullah praktek pernikanan (main mata) antara muhallil dan muhallal lah dianggap sebagai pelacuran ${ }^{29}$.

\section{Konsep Hiilah dalam Hukum Islam}

Konsep hiilah merupakan konsep yang dibahas oleh hampir para ulama', lebih-lebih ulama' Ushul Fiqh. Besarnya ulama' terhadap konsep hiilah menandakan akan urgensitas konsep hiilah dalam hukum Islam. Namun demikian, konsep hiilah merupakan salah satu konsep yang sulit. Hal ini disebabkan dalam al-Qurán atau Hadits sama-sama terdapat contoh yang melegalkan hiilah dan juga contoh yang melarang hiilah.

Abu Sulaiman dari kalangan ulama' Hanafiyah meniscayakan bahwa mereka yang menentang konsep hiilah sama halnya telah mengingkari pada ajaran yang dibawa oleh Nabi Muhammad ${ }^{30}$. Namun demikian dalam praktiknya, tidak sedikit ulama' yang enggan menggunakannya karena hiilah justru berakibat pada menghalalkan perbuatan yang diharamkan

${ }^{28}$ Al-Baihaki. As-Sunan al-Kubra lil Baihaki. Maktabah Syamilah. Juz 7 hlm 208.

${ }^{29}$ Ahmad ibn Abu Bakar al-Bushiri. Ittihal khairoh al-mahroh. Maktabah Syamilah. Juz 4 hlm 109.

${ }^{30}$ Hanafiy. Al-Asybah wa an-Nazhoir Hanafiy. Maktabah Syamilah. hlm 443. 
atau bahkan mengharamkan yang dibolehkan sebagaimana tertera dalam ancaman hadits.

Ibn Hajar menjabarkan bahwa konsep Hiilah dapat terealisir dengan beberapa teknik hiilah:

1. Hiilah dipakai dengan cara yang diperbolehkan untuk membatalkan yang benar atau untuk menetapkan yang salah; hiilah dengan cara ini adalah haram.

2. Hiilah dipakai dengan cara yang diperbolehkan (memang) untuk menetapkan yang benar dan membatalkan yang salah; hiilah jenis ini hukumnya sunnah bahkan wajib.

3. Hiilah dipakai dengan cara yang diperbolehkan untuk menyelematkan agar tidak terjebak pada hal-hal yang dimakruhkan; hiilah jenis ini hukumnya Sunnah, setidak-tidaknya boleh (mubah).

4. Hiilah dipakai dengan cara yang diperbolehkan untuk meninggalkan perbuatan yang disunnahkan. Hiilah jenis ini hukumnya makruh.

Namun demikian, Ulama' justeru berbeda pendapat tentang konsekuensi hukum wadl'iy perbuatan hasil dari hiilah jenis pertama. Apakah sah baik secara dhohir (normatif) atau bathin (substansial), atau tidak sah secara mutlak, atau sah secara dhohir saja namun berdosa melakukannya ${ }^{31}$. Perbedaan dalam menyikapi konsekuensi hukum wadl'iy perbuatan hasil dari hiilah jenis ini disebabkan karena perbedaan dalam penggunaan, penafsiran.

Asy-Syatibi membagi hiilah menjadi tiga macam.

1. Hiilah yang mutlak haram yaitu hiilah yang dilakukan oleh orang-orang munafik. Mereka menampakkan dan berpura-pura Islam sementara hatinya tetap berada dalam kekafiran.

2. Hiilah yang mutlak dibolehkan yaitu hiilah yang dilakukan oleh seorang muslim yang mengucapkan/melakukan perbuatan kufr secara terpaksa.

3. Hiilah yang masih diperdebatkan.

Sementara Ibn Qoyyim mengklasifikaan hiilah menjadi dua:

${ }^{31}$ Ibid. Ibn Hajar. Fathul Bari. Hlm Juz 19 hlm 417. 
1. Hiilah yang disyari'atkan (حيلة مشروعة) yaitu hiilah yang dipakai sebagai solusi terbebas dari perbuatan dosa menuju perbuatan yang dihalalkan/dibenarkan, atau justeru untuk menolak kebatilan. Hiilah jenis ini adalah hiilah yang tidak menabrak dasar-dasar syari'at dan juga tidak menabrak mashlahat syari'at. Hiilah jenis ini terbagi menjadi 3 bagian lagi:

a. Hiilahnya diharamkan untuk tujuan yang dibenarkan. Seperti contoh seseorang berada dalam kebenaran, namun dia tidak mempunyai bukti atau saksi. Untuk menyelamatkan hak dan keberannnya, lalu dia membayar seseorang sebagai saksi (saksi palsu).

b. Hiilahnya disyari'atkan untuk tujuan yang disyari'atkan. Hiilah jenis ini adalah hiilah yang dipakai dalam berbagai bidang hukum Islam.

c. Hiilahnya belum ada ketentuanya dalam syari'at lalu seseorang menggunakannya untuk tujuan yang dibenarkan ${ }^{32}$.

2. Hiilah yang diharamkan (حيلة كحرمة) yaitu hiilah yang digunakan untuk tujuan yang diharamkan, membatalkan perkara yang benar, atau menjadikan perkara batil jadi samar-samar. Hiilah jenis ini adalah hiilah yang bertentangan dengan dasar-dasar syari'at atau bertentangan dengan mashlahat syari'at. Hiilah jenis ini juga terbagi menjadi tiga bagian:

a. Hiilahnya diharamkan untuk tujuan yang diharamkan. Contohnya seseorang yang (terlanjur) menceraikan isteriinya dengan talak 3, lalu dia mencari-cari alasan agar terhindar dari kewajiban muhallil dengan cara mencari-cari alasan dengan mengatakan bahwa pernikahan yang dilangsungkan mengandung cacat.

b. Hiilahnya pada dasarnya dibolehkan namun digunakan untuk tujuan yang diharamkan. Contoh seseorang melakukan perjalanan, namun dengan tujuan untuk merampok.

c. Hiilahnya belum ada ketentuannya dalam syari'at, lalu digunakan untuk tujuan yang diharamkan. Seperti seseorang (sebenarnya) hendak memberi wasiat kepada ahli warisnya, namun lalu kemudian dia justeru melakukan ikrar untuk melakukan wasiat kepada ahli

${ }^{32}$ Ibn Qoyyim. Sad adz-Dzara'i wa tahriim al-Hiyal li Ibn Qoyyim. Maktabah Syamilah. Juz 1 hlm 24. 
waris (hiilah melakukan ikrar wasiat untuk menghindar dari ketentuan waris) ${ }^{33}$.

Jika ditarik benang merah, Ibn Qoyyim ataupun as-Syatibi pada dasarnya sepakat pada dua hal; yaitu hiilah yang diharamkan, dan hiilah yang disyariáhkan. Namun demikian, terdapat satu problem hiilah yang sulit dipecahkan, yaitu hiilah yang kondisinya masih samar-samar. Hillah yang samar-samar ini akan terlihat dalam contoh aplikasi hukum Islam sehari-hari. Contohnya, seseorang yang mempunyai harta sampai satu nishob, lalu menjelang sampai satu tahun (haul) dia lalu mentashorrufkan (membelanjakannya) dengan cara memberikannya pada anaknya. Dengan cara ini, hartanyapun berkurang dari satu nishob, sehingga kewajiban zakat menjadi gugur. Nah, dalam kasus ini perbuatan mentashorrufkan harta apakah termasuk dalam hiilah yang disyari'atkan ataukah justru hiilah yang diharamkan. Dalam kasus ini, ulama' berbeda pendapat. Ulama' Hanafiyah dan Syafi'iyah berpendapat boleh, sementara ulama' Malikiyah dan Hanabilah menyatakan keharamannya. Alasan yang dikemukakan ulama' Hanafiyah dan Syafi'iyah bahwa perbuatan yang diperbolehkan (yaitu mentashorrufkan harta) tetap diperbolehkan, kalaupun berakibat pada hilangnya kewajiban zakat (karena kewajiban zakat) belum datang. Sementara ulama' Malikiyah dan Hanabilah berpendapat bahwa perbuatan tersebut merupakan perbuatan yang disengaja untuk menghilangkan kewajiban.

Sebagai ketentuan Ibn Hajar dalam Fathul Bari lalu memberi catatan, bahwa ketentuan kebolehan hiilah dikembalikan pada tujuan akhir dari perbuatan hiilah tersebut. Jika tujuannya agar terbebas dari perbuatan dosa dan maksiat maka boleh (bagus) namun jika justru terbebas dari sebuah kewajiban maka tidak boleh bahkan berdosa ${ }^{34}$.

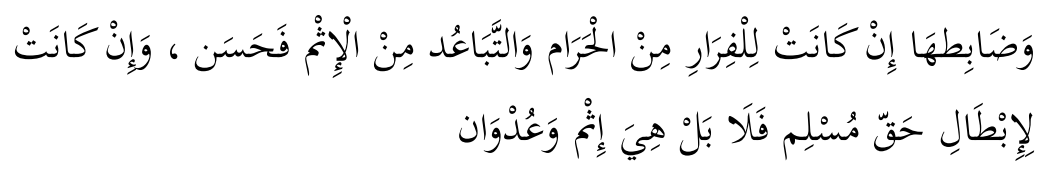

${ }^{33}$ Ibid. Ibn Qoyyim. Sad adz-Dzara'i wa tahriim al-Hiyal li Ibn Qoyyim. Juz 1 hlm 25.

${ }^{34}$ Ibid. Ibn Hajar. Fathul Bari. Juz 19 hlm 417 
Ketentuan yang diberikan Ibn Hajar mana hiilah yang boleh dan yang tidak boleh saat diaplikasikan dalam kasus lain belum komprehensif. Dalam kasus pernikahan muhallil, catatan Ibn Hajar tidak bisa diaplikasikan. Catatan Ibn Hajar menemui kebuntuan saat melakukan hiilah dalam pernikahan muhallil untuk kepentingan muhallal lah. Dalam kasus pernikahan muhallil, catatan Ibn Hajar tidak bisa diaplikasikan karena melakukan hiilah dengan usaha menghindar dari perbuatan haram justru bertentangan dengan nash yang lain, yaitu ancaman dari melakukan pernikahan tahlil sebagaimana dalam hadits. Untuk mengatasi kebuntuan ini, Walid Ibn Rasyid as-Saídan memberikan alternatif solusi. Jika seseorang menikahi perempuan yang tertalak 3 dengan maksud menjadi hiillah bagi suami pertama maka hukumnya haram sebagaimana larangan dalam hadits, dan jika menikahinya karena dasar rasa sayang dan keinginan menikahinya maka boleh. Dengan demikian, kesulitan dalam penentuan hiilah masy'ruáh dan hiilah muharromah akhirnya dikembalikan pada aspek paling dasar dalam sebuah perbuatan yaitu niat ${ }^{35}$.

Selain itu, Moh. Imron Rosyadi menuliskan bahwa hiilah tidak berdiri sendiri. Penerapan konsep hiilah seringkali dibersamakan dengan penerapan konsep lain, seperti konsep darurat, istihsan, mashlahah dan konsep-konsep dalam metodologi ushul fiqh yang lain. Dengan catatan ini, penerapan hillah dapat dipertanggungjawabkan ${ }^{36}$.

\section{Kesimpulan}

Hiilah merupakan sebuah konsep dalam hukum Islam untuk menyelesaikan problematika hukum Islam. Konsep hiilah sendiri diintrodusir oleh Qur'an dan Hadits. Introdusir Qur'an dan Hadits tentang konsep hiilah terpetakan dalam dua bentuk yaitu hiilah masyru'ah sebagai solusi dan yang kedua hiilah muharromah sebagai sebuah manipulasi terhadap hukum Islam. Kesulitan penerapan konsep hiilah terjadi saat

35 Walid Ibn Rasyid as-Saídan. Risalah fi Tahqiq Qawaid an-Niat. Maktabah Syamilah. hlm 30 .

${ }^{36}$ Mohammad Imron Rosyadi. Hiilah al-Hukmi, Studi teori perkembangan Hukum Islam. Jurnal al-Mashlahah IAIN Pontianak. Vol 12 no 12016. 
hendak diaplikasikan dalam kasus-kasus hukum tertentu. Hal inilah yang kemudian memunculkan klasifikasi yang ketiga yaitu hiilah yang masih samar-samar. Oleh karena terjadi kesulitan dalam penentuan kriteria hiilah yang samar-samar inilah, maka kriterianya dikembalikan pada konsep dasar dalam tiap perbuatan mukallaf yaitu niat.

\section{DAFTAR PUSTAKA}

Ahmad. Musnad Ahmad al-Risalah. Maktabah Syamilah.

Al-Anshori, Zakariya. Ghayatul Wushul Fi Syarhi Lubbil Ushul. Surabaya: alHidayah. Tt.

Al-Baihaki, Abu Bakar Ahmad Ibn Husain Ibn Ali. As-Sunan al-Kubra lil Baihaki. Maktabah Syamilah.

Al-Bushiri, Ahmad ibn Abu Bakar. Ittihaf al-khairoh al-mahroh. Maktabah Syamilah.

Al-Jauziyah, Ibn Qoyyim. Sad adz-Dzara'i wa tahriim al-Hiyal li Ibn Qoyyim. Maktabah Syamilah.

Al-Khodlriy. Musnad Abi Áwanah. Maktabah Syamilah.

Al-Mahalli, Syamsuddin. 2003. Hasyiyah al-Allamah al-Bannani ála Matn Jamíl Jawami'. Beirut Lebanon. Dar al-Fikr.

Al-Quzwaini, Muhammad Ibn Yazid Abu Abdillah. Sunan Ibn Majah. Maktabah Syamilah.

As-Saídan, Walid Ibn Rasyid. Risalah fi Tahqiq Qawaid an-Niat. Maktabah Syamilah. 
As-Suyuthi. Jami'al-Hadits li as-Suyuthi. Maktabah Syamilah.

At-Thobari, Abu Jakfar Muhammad Ibn Jariir. Jami'ul Bayan fi Tafsiril Qur'an lit Thobari. Maktabah Syamilah.

Buchori, Muslim. Al-Jamú Baina al-Shohihain li Buchori Muslim. Maktabah Syamilah.

Hanafiy. Al-Asybah wa an-Nazhoir Hanafiy. Maktabah Syamilah.

Hijaziy, Muhammad Mahmud. At-Tafsir al-Wadhih. Maktabah Syamilah.

Jalaluddin, Syaikh. Tafsir Jalalain. Maktabah Syamilah.

Muhadjir, Afifuddin. Membangun Nalar Islam Moderat. Situbondo: Tanwirul Afkar.

Nujaim, Ibn. Al-Asyah wa al-Nazhair li ibn Nujaim. Maktabah Syamilah.

Rosyadi, Mohammad Imron. Hiilah al-Hukmi, Studi Teori Perkembangan Hukum Islam. Jurnal al-Mashlahah IAIN Pontianak. Vol 12 no 1 2016 